\title{
O Serviço da teologia para a vida de Deus
}

Bárbara Bucker, $m c$

Nesta comunicação desejo partilhar com meus colegas professores e com todos os estudantes, o sentido e a tarefa da formação teológica na PUC/RJ.

\section{Princípios fundamentais da docência acadêmica da teologia.}

A teologia cristã está centrada em torno à pessoa de Jesus Cristo, enviado do Pai ao mundo para dar-lhe a salvação. São João explica esta missão como um ato de amor: "Tanto amou Deus o mundo..." (João 3,16). Por isso, o Evangelho é a Boa Notícia do Infinito Amor de Deus por cada um dos seus filhos e filhas, amor que se revelou pela presença de Jesus Cristo.

Ao colocar esta base em minhas reflexões quero recolher o Magistério de Bento XVI em sua primeira Encíclica, "Deus é caridade", já que propõe para toda a Igreja, algo assim como seu programa fundamental. No mundo atual, em que se debilita a fé e a confiança nas instituições das religiões tradicionais, podemos perguntar-nos se tal fato não se deve talvez, à ausência de uma experiência profunda religiosa. O dominicano Carlos Josaphat em seu livro: "Falar de Deus e com Deus. Caminhos e descaminhos das religiões hoje", Paulus, 2004, dedica sua obra a todos aqueles e aquelas que buscam os caminhos da Fé, da oração e da solidariedade enfrentando um ateísmo 
camuflado e sofrendo na quase desesperança de tanto ver banalizado o Evangelho no lucrativo. Daí, meu interesse em partilhar o que segue.

O "espaço" de nossos cursos deveria ser um "espaço especial", um clima diferente, onde o interesse primário não se limita à formação acadêmica, senão que o transcende provocando uma experiência de liberdade vivida no gozo e esperança. Trataria de reproduzir aquele axioma constantemente repetido por João Paulo II: "a verdade nos fará livres". A verdade sobre Deus é tão cheia de riqueza, e engloba tantas dimensões, que se dirige ao ser humano em sua totalidade.

$\mathrm{Na}$ teologia, a separação entre os enunciados racionais e as atitudes vitais se faz impossível. Como seria, falar do Amor de Deus, se nosso coração está fechado ao amor para com o próximo? Como tentar apresentar uma imagem da Paternidade de Deus, se a experiência mais imediata de nossa fraternidade recíproca é uma negação dessa verdade fundamental?

Temos um patrimônio comum das religiões nascidas da Bíblia, as mesmas que se encontram nos limites de nações que se tornaram vulcões de terríveis guerras e destruições, sinal de nossa impotência para que Deus seja "nossa paz".

O desafio da teologia cristã, não é só apresentar uma "teologia bíblica", revelada; senão especificamente "neo-testamentária". Precisamente num momento histórico onde necessitamos com urgência do diálogo religioso entre todos os crentes num Ser divino, temos o dever de contribuir com aquilo que nos caracteriza, que nos faz "original", sem que por isso nos consideremos superiores aos demais. Somos sim, responsáveis de uma gratuita eleição para algo que devemos testemunhar.

Esta verdade que nos é confiada é o humilde serviço testemunhal e não imposição doutrinal autoritária. $\mathrm{O}$ diálogo Inter-religioso será tanto mais profundo e rico quanto mais nos aproximemos daquele Deus que é amor e que por sê-lo, é verdade para nossas inteligências e luz para nossas ações.

Quais as exigências racionais e afetivas que têm a fé num Deus que se apresenta pelo envio de seu Filho ao mundo? O Evangelho nos revela que esse Deus, a quem os judeus louvavam dizendo "Bendito seja Jahvé", os cristãos acolhem dizendo: "Bendito seja o Pai de Nosso Senhor Jesus Cristo". O caráter trinitário da teologia implica o caráter cristológico.

Esta Revelação nos diz que o ser humano é imagem de Deus. Tal exigência de fé nos leva a destacar a dignidade da pessoa humana e de sua história neste mundo, de um modo característico, do qual somos responsáveis todos os crentes. Marca uma especial atitude de profundo respeito pela humanidade. 
Maria, a mãe de Jesus aparece, por uma parte, como representante do gênero humano, que não só buscou incessantemente Deus, senão que foi escolhida como parte da humanidade; e por outra parte, como mulher, para a realização dos planos da salvação do gênero humano. Ela foi o primeiro ser humano da história em ter o conhecimento do mistério. Assim se manifesta que os desígnios do Pai de enviar seu Filho ao mundo, eram também os desígnios de que fosse "nascido de mulher", parte de uma humanidade histórica. Em Maria está o germe da Igreja, de todos os que acolheram a revelação e vivem dela e para ela.

O desígnio do Pai de entregar seu Filho ao mundo passa pela "cumplicidade" de uma comunidade humana que se abriu pela fé ao mistério. E isso, pela simples razão de que Deus quer que sua Palavra venha por meios humanos, por caminhos humanos, por cultura humana. A Encarnação seria um mistério insuspeitável se não tivesse uma comunidade na que lhe foi anunciada e viveu esse desígnio de Deus como experiência, para dar testemunho para o mundo.

Ensinar teologia é apresentar o mistério da filiação de Cristo, mas isto tem sentido se existe uma comunidade humana na que este mistério é apresentado. Quando um grupo humano está batizado na mesma fé, se dá conseqüentemente esta base comum. A PUC considera esta base comum mesmo que reconheça o fato da pluralidade de crenças nos alunos que a freqüentam.

Neste sentido, o curso de ética cristã tem um duplo cometido: ajudar ao crente a aprofundar as exigências morais de sua fé, e a apresentar ao não crente, os fundamentos racionais dessas condutas como algo pertinente ao progresso humano. Fechar-nos exclusivamente na ética "cristã" enquanto tal, ainda que seja um objetivo legítimo da própria instituição, não respeitaria o fato do pluralismo de crenças, nem tampouco ajudaria ao sentido evangelizador, de poder dialogar com outras éticas -sobretudo de origem não religiosas- como é o caso freqüente em nosso mundo secularizado sobre a base de pressupostos comuns.

A tradição eclesial escolheu sempre o caminho de fundamentar os ensinamentos da Igreja não só nos dados da fé, senão também da razão através do "direito natural".

Estes fundamentos teológicos, que se explicitam como trinitários, cristológicos e eclesiológicos, são os que dão sentido ao nosso serviço de teologia na PUC. Professores e estudantes estão chamados a dar testemunho de um novo sentido da palavra "Deus", "Cristo", e "Igreja", na encruzilhada das religiões e dos problemas da atualidade. Mas, não basta ter clareza enquanto ao conteúdo do que se ensina; faz-se necessário confrontar também a experiência de nossa prática. 


\section{O problema de nossa práxis de docência acadêmica.}

Desde a prática do ensino lembro inesquecíveis experiências gratificantes, mas também interrogantes, inquietudes, desejos de melhorar. Desde estas experiências com seus sinais positivos e negativos desejo aprofundar as dificuldades objetivas que têm o ensino da teologia e em particular da ética cristã na universidade. Interessam-me também as projeções do serviço teológico para além das fronteiras do Acadêmico dentro de nossa instituição, tal como se expressa no Programa de Teologia a Distância.

\section{a) Experiências encorajadoras:}

As experiências encorajadoras eu as vivi em muitas ocasiões, ao ver como as jovens e os jovens vão encontrando o caminho para orientar o sentido de sua vida através do curso de Ética Cristã. Foi para mim uma experiência muito gratificante ver os alunos que se abrem à verdade da vida humana, que refletem com profundidade sobre o seu próprio destino, que querem tomar em suas mãos seu próprio futuro; que se sentem responsáveis do mundo que vão desde já criando passo a passo. Quero destacar, sobretudo, dois aspectos, muito significativos na etapa da juventude, na que se encontra quase a totalidade de nossos estudantes.

b) Aprofundar no sentido da liberdade.

É gratificante participar no crescimento e amadurecimento do exercício da liberdade; na responsabilidade de tomar distância por uma crítica sadia para da cultura que vivemos cultura que muitas vezes nos adormece e massifica.

Constato na juventude duas atitudes opostas, a do acomodar-se a essa cultura, vegetar nela; e a de mudá-la, transformá-la, porque é insuficiente, empobrecedora. A etapa da vida que chamamos de juventude é mais sensível à pobreza da inautenticidade nas relações humanas. Isto é positivo e denota uma riqueza interior que não consegue ser expressa no mundo em que vivem. Mas, tem também um aspecto adverso, quando a crítica e a denúncia fecham o exame de realismo sobre as possibilidades de transformações reais.

Parece que é um índice de maturidade e sentido de responsabilidade o não só ver as lacunas e defeitos, mas também ver pistas construtivas e realistas para alternativas de um mundo diferente. A experiência da vida nos ensina que muitos esforços ficaram truncados por nosso ser limitado; apesar de nossas boas intenções. São momentos de crises, de impaciência. 
Para um educador da juventude, esta presença amiga ao lado de momentos de crises, se assemelha aos sentimentos de compaixão e de ternura de uma mãe que vê os pequenos fracassos de seus filhos. É saber estar ao lado, sem substituir os processos que devem ser realizados pela pessoa mesma. Talvez a imagem materna implique, para muitos, um mero aspecto sentimental e ao mesmo tempo, supõe uma autoridade familiar. Por isso, prefiro substituí-la pela de companheiras e companheiros num mesmo caminhar, na solicitude pelos demais, também no exercício que dentro do âmbito institucional acadêmico supõe o propor um ensino, do qual devemos dar conta também às instâncias de autoridade eclesial.

Como professora de Ética Cristã eu creio que é de minha responsabilidade dar testemunho de que em Cristo nos foi dado o caminho da verdadeira liberdade, caminho que não é do "capricho" arbitrário, mas o de servir aos demais de modo que eles mesmos possam ser capazes de disporem de suas vidas. A grandeza da liberdade humana se mede pela grandeza da causa à que se entrega essa liberdade. Gostaria de ser testemunha diante dos jovens que meu crescimento como pessoa está vinculada à profundidade da vivência de Cristo em mim, libertando-me de meus medos e egoísmos para que a liberdade de Cristo me leve ao respeito de cada um de meus estudantes.

\section{c) Aprofundar no sentido do amor.}

É gratificante, sobretudo, a descoberta do sentido do amor, do respeito. A juventude é uma etapa da vida ou um estado de espírito, propício para chegar à grande sabedoria do significado do amor, sabendo que é mais que a atração e o gozo, porque é também aceitação das qualidades próprias e alheias, disposição para o sacrifício e a doação.

Para dizê-lo com uma breve fórmula: é a descoberta de que a "felicidade" não pode se separar da "fidelidade", e que as decisões afetivas do presente têm que se fazerem sólidas como os compromissos de amor para o futuro da vida. $\mathrm{O}$ amor, assim entendido, é encontro de pessoas, encontro de histórias que se unem para formar no futuro uma única história.

Sei muito bem que estes frutos não são exclusivos das aulas; existem muitas influências (familiares, sociais, institucionais na Universidade, pastorais nas Paróquias e comunidades de fé). Mas, penso que, talvez, a etapa de estudos lhes permite ordenar, e compreender melhor a si mesmo, tendo algumas categorias para aprofundar problemas e encontrar caminhos de respostas.

Não devemos esquecer nunca que a Universidade não é uma "fábrica de objetos" nem de processos de massificação, senão uma "escola dos espaços de sujeitos", marcados cada um pelo selo inconfundível de sua irrepetível identidade. 
As relações entre Igreja e Cristo nos oferecem um modelo das relações para a juventude, desde a amizade até o compromisso mais sério e profundo de noivado e matrimônio. As relações do mistério eclesial e cristológico são de total doação de um para o outro, de fazer feliz a outra pessoa. Supõe por parte de cada um, uma renúncia a todo egoísmo, e uma vinculação que não nasce do poder da lei senão da força do amor.

Encontro neste dado da fé um convite ao testemunho de que a comunidade eclesial tem que unificar-se desde e para o amor a Cristo. Quando há amor há comunhão livre de vontades; quando não há amor, se tenta esta unidade pelos caminhos da lei, que nunca asseguram a aceitação profunda da vontade do outro nem a realização sincera da colaboração.

A lei do amor, o único mandamento que Jesus nos deixa, é ao mesmo tempo percebida como tensão e reconciliação tanto da lei como do amor, para evitar que a liberdade se converta em libertinagem e que o cumprimento da lei nos despersonalize e nos converta em "robôs", como puros executores de tarefas.

d) Experiências dificeis.

Em minha experiência não só existem as gratificações, os momentos "pascais de ressurreição", senão também os momentos difíceis. E, tudo isso faz parte da minha vida e da vida das pessoas ao meu redor. Algumas experiências difíceis nascem das limitações de tempo e capacidade. Gostaria de estar mais disponível para os alunos, para as entrevistas personalizadas. Poder tratar a cada um e cada uma como um ser pessoal digno de minha atenção, de meu respeito, de meu carinho. Mas, isto não é possível pela mesma organização da vida universitária: horários rígidos, inflexíveis, acumulados para aproveitar em pouco tempo muitas atividades.

Sou também consciente das limitações de conhecimentos; por muito que me esforce em dominar as áreas de meu trabalho profissional, ficam ainda muitas relações com outras disciplinas extra-teológicas, mas que formam parte dessa grande verdade do humano. $\mathrm{O}$ reconhecimento de meus limites é parte de minha "cruz", de saber-me um ser humano, que não é Deus; e que como todos os seres humanos está sujeito ao erro e à retificação. Mas, creio que quando pude viver este aspecto, dei também testemunho de integridade e de amor à verdade.

As limitações de conhecimento podem diminuir pela atividade de diálogo interdisciplinar na Universidade. O título mesmo de "Universitas" se refere ao encontro de todos os saberes. Mas, nem sempre nos organizamos para o diálogo interdisciplinar. Tudo isso é possível na mesma Universidade, nas facilidades que existem ou podem existir para um diálogo profundo e dinamizador. Creio que depende de mim o manter o espírito vigilante, aberto 
às novas correntes de pensamento, as novas conquistas da ciência, às novas revelações de personalidades ricas.

Mas, creio que devo aceitar estas duas limitações com sentido realista: o tempo de que disponho é o real e limitado; as capacidades são também as que eu tenho ainda que desejo crescer e ter mais conhecimento para poder servir melhor.

e) Experiências de frustração pela liberdade: minha e dos demais.

Outras vezes experimento a frustração por algo que é exterior a minha própria pessoa e que depende da liberdade e da vontade dos outros. A que mais me fere é a desorientação de alguns jovens. Nestes se revela o crescimento da vida, a superação das etapas infantis e da adolescência para uma maturidade de uma juventude verdadeiramente humana. É muito bonito ver a vida e contemplá-la, sentindo-a aberta aos mistérios do futuro. Mas, sei que como na parábola do evangelho, coexistem o trigo puro e a cizânia destrutiva. Vejo nos jovens, o legítimo desejo de afirmar sua personalidade e liberdade; mas também às vezes, os sinais de expressão deste dom tão humano que se confunde com indisciplina, agressividade, rebeldia. A "afirmação de si" tende a aparecer como a "negação do outro", como se fosse um dilema ou um conflito nas relações interpessoais.

É certo que estes casos não constituem a maioria. Mas, é meu dever e meu desejo ajudar aqueles que se encontram num momento difícil, dizer-lhes que cada um tem dentro de si riquezas de grande valor, mas que se misturam também com manifestações, idéias nem sempre retas. E, no entanto, apesar de meus bons desejos e intenções, tenho que aceitar que a liberdade é um reduto inviolável e prefiro que as condutas que brotam da juventude sejam autênticas, não pelo medo ou o castigo senão pela convicção e a decisão livre.

f) Um desafio de buscarmos juntos, caminho.

Confio no poder da razão para buscar juntos os caminhos da convivência, para eliminar os maus entendidos, as oposições e os conflitos que destroem nossa relação. Creio que isto é uma prova não de ortodoxia teológica, mas sim de ortopraxis da fé; e sei que nem sempre estamos à altura de viver as exigências do Evangelho.

É aqui onde creio que necessitamos de algum argumento existencial, simples e claro que possa servir para confrontar nossa conduta. Trata-se de "pôr-se no lugar do outro", o que não é senão, uma tradução psicológica de um imperativo ético: amar ao próximo como a si mesmo.

Minha experiência de vida, diz que as exigências de meus pais e de meus mestres em muito me enriqueceram. Agora, posso alegrar-me desta disciplina que forjou em mim a pessoa capaz de compreender hoje o sentido 
de muitas realidades existenciais. Digo aos jovens: não façam agora o que não quereriam ter feito quando olhem sua vida desde outra perspectiva; não façam aos outros, o que não quereriam que lhes fizessem.

Tenho encontrado inúmeras atitudes nobres por parte de alguns de meus alunos que, convidados para uma reflexão mais profunda entre docência e sua condição de estudantes, reconheceram a necessidade de construirmos juntos, um caminho de atitudes razoáveis! Momentos, em que eles sabem reconhecer por parte dos educadores, a compreensão do que é mais valioso e autêntico, que levam dentro de si, mas que num mundo enormemente competitivo parece que deve ser ocultado para defender-se a si mesmo.

Por isso, gostaria de ajudar àqueles que passam por momentos de rebeldia, a entender bem as razões profundas que podem existir e expressá-las de forma construtiva para a comunidade estudantil e acadêmica, mas não de forma destrutiva e paralisante.

g) Fraca motivação para os cursos de Teologia ou de Ética Cristã.

Outras experiências frustrantes se explicam quando os alunos não estão suficientemente motivados; quando a formação religiosa é, para eles, uma dimensão imposta pela estrutura universitária, e lhes parece como algo marginal ao seu progresso profissional.

Creio que em sua raiz, está a desmotivação que é o resultado de uma cultura da "eficácia tecnológica" onde todos, estamos envolvidos. Somos examinados pelo que fazemos, e não pelo que queremos ser e estamos sendo. Valorizam-se os produtos de nosso estudo e não a maturidade de nossa inteligência, o equilíbrio de nossa vida emocional, a clareza de nossas visões diante da vida.

\section{Teologia e ética na sociedade tecnológica.}

Os cursos de teologia, e entre eles os de Ética Cristã, não vão na linha do conhecimento tecnológico e das disciplinas acadêmicas mais afins com esses resultados. Tem outro objetivo: fazermos crescer como pessoas, desenvolver o sentido de nossa fé para vivê-la num mundo cada vez mais complexo e com maiores desafios.

Aqui se encontra a tensão entre a identidade institucional de uma Universidade que se considera "católica" e que tem certos requisitos, e os motivos pessoais dos alunos ao buscar esta Universidade. A Universidade pretende formar integralmente as pessoas; e aparece que a sociedade espera somente que se preparem "técnicos". O processo é tão interiorizado que as 
pessoas chegam só a valorizar-se enquanto profissionais, como se existisse uma distancia entre seu ser humano e sua atividade profissional.

Por isso, apesar de que o crescimento humano pessoal seja tarefa que concerne ao mais íntimo e sagrado que cada um tem em sua vida, da qual é totalmente responsável enquanto que cai sob sua capacidade de autodeterminação. Esta tarefa não é valorizada como prioritária, no afã de conseguir as metas que a sociedade espera de nós em relação ao status social, à competência profissional: em uma palavra, em torno ao nosso "fazer", que irá refletir-se, depois em nosso "ter". A pergunta pelo "ser" pode parecer muito "metafísica" e abstrata, apesar de tocar o que cada um de nós é "radicalmente"; quer dizer, em suas próprias raízes, da qual nascem os frutos que aparecem em nossa convivência humana.

Um grande mestre da ética, Platão, se perguntava se uma ciência que ajuda ao ser humano "atuar como bom ferreiro" é suficiente para viver bem a sua própria humanidade, e diz que não basta ser "bom ferreiro", senão que se tem que ser por cima de tudo, "bom ser humano".

Quando falo de formação integral não é porque despreze a qualidade profissional, senão porque não deve se "absolutizar", mas "integrar" na totalidade das dimensões da vida humana.

A pergunta da identidade da Universidade tem aspectos que devem ser considerados, porque nem todos os alunos são católicos; alguns não são cristãos nem crentes. Pela natureza da fé cristã, o tema religioso não pode ser problema de imposição, mas certamente de proposição.

É desafio e tarefa dos educadores, apresentar com simplicidade e transparência os conteúdos da doutrina e as exigências morais da fé cristã.

É precisamente no contexto do dogma cristão, que tem seu eixo fundamental na Encarnação do Filho de Deus, que nos encaminha a valorizar profundamente o humano que existe em cada um de nós e em nossos semelhantes. Ninguém pode temer que seja qual for o credo ou suas crenças, porque não se verá incompreendido ou não respeitado na nossa Universidade; mas podemos esperar também que de sua parte, respeitará as finalidades e objetivos de uma instituição universitária que se funda na fé cristã e que aspira a formar pessoas que vivam coerentemente sua fé.

A chave para poder oferecer contribuições significativas a esta juventude em sua formação ética e religiosa, encontra-se na motivação dos próprios educadores.

Creio que é importante uma concepção de que a educação não pode reduzir-se a oferecer uns conteúdos para a inteligência, mas estímulos para as vivências concretas da fé, motivos para respostas práticas. 


\section{Para projeções sociais de nosso fazer universitário.}

Não basta que cada membro da Universidade, estudante ou professor trate de viver com coerência humana e cristã os valores que a instituição acadêmica manifesta professar. Trata-se também de uma abertura já atual e não só futura, da instituição e não meramente por iniciativas privadas, para a vida na Sociedade e na Igreja.

Por isso, quero destacar o significado do programa de extensão da Teologia a Distancia. Como idéia é uma intuição muito oportuna para multiplicar os frutos de um trabalho já realizado em nível interno da Academia, que germina em outros espaços. Quero valorizar os esforços de todos os professores do Departamento de Teologia e da Equipe de colaboração dos corretores de provas, serviço de tutoria, etc.

Creio que é por aí, onde caminhamos, dando um testemunho de trabalho em equipe, entusiasmado com a obra, sem buscar protagonismos pessoais; somos servidores, dando aos demais algo do muito que temos recebido, e tratando de serviço à fé que é intrínseco à própria teologia, nossa dívida é primordialmente com Deus mesmo, com a Igreja e com esse povo simples que busca aprender com avidez, sedento de formação, de conhecimentos, de orientações morais.

Um dos significativos testemunhos recebidos na conclusão do último curso pela Diocese de Itaguaí foi com a palavra da oradora de um dos grupos deste curso.

\section{Solenidade de Conclusão do Curso de Iniciação Teológica a Distância por Tutoria.}

- Não sei como falar; os assuntos são diversos; mas como vocês sabem; só sei expressar em prosa e verso.

De repente nossa vista clareou, aos dezessete dias de abril no ano de dois mil e quatro no Colégio Cembra no Município de Paraty iniciou-se o Curso de Teologia Para Ti e Para Mim.

Mais de noventa alunos, eufóricos, ansiosos que deram o seu sim.

- A equipe de professores composta de Padres, Irmãs e o Bispo D.José Ubiratan nos acolheu especificando os objetivos:

Formação e crescimento na fé, grande motivo!

Nós falamos do que conhecemos para abrir a nossa mente, nosso coração, conhecer mais, para amar mais e consciente.

- Não deve existir incompatibilidade entre ser sábio e santo; entre ficar com uma pessoa muito santa e outra sábia. 
É muito melhor ficar com a sábia, pois a verdadeira sabedoria busca a Santidade.

É necessário ter o conjunto: sabedoria e santidade.

Vivendo, estudando e conhecendo mais e mais a verdade, mergulhando no mistério da Santíssima Trindade.

A professora Tereza nos encorajou com as palavras:

Devemos ter a determinação do Povo de Deus.

Encontrar e dialogar com o primeiro amor.

Refazer o Caminho na busca de crescimento e de fé.

Organizar com os colegas, o círculo de estudo sobre Deus.

\section{O curso de Iniciação Teológica distribuído em quatro blocos:}

Núcleo Temático - Bloco A - Encontro com a palavra viva

Antigo e Novo Testamento - Descobrindo o objetivo do Êxodo

Nós tentamos conciliar entre família, trabalho, a nossa vida, disposição, empenho, garra, perdemos o medo!

Nos Seminários que foram no total de nove:

Encontro com Deus que se revela Jesus Cristo Vivo;

O Cânon bíblico, o rosto que a Igreja deu as Escrituras.

Em cada unidade constatamos a dimensão do compromisso.

Bloco B - Antropologia como foi envolvente!

A graça de Deus que nos é oferecida para acolher o Reino!

Que tema! Surpreendeu muita gente!

Comunhão, responsabilidade, desenvolvimento humanizante; o passado iluminando o presente.

Blocos C e D - Trindade e Eclesiologia

Lamentavelmente alguns desistiram. Não puderam continuar; comunicaram. Uma das nossas companheiras foi morar no céu, batalhadora e guerreira, a amiga Aglais, hoje está junto de Deus, é mensageira.

Ficamos com saudades, mas nos conformamos, pois só Deus não é passageiro.

Para finalizar o nosso estudo, vimos a Bio-ética.

Refletimos o confronto com muitas realidades, clonagem, aborto, genoma, eutanásia, manipulação genética.

Para garantir a dignidade humana e ter uma vida de qualidade. Devemse aliar a ciência e a ética.

Quantas noites sem dormir!

Ás vezes, dores de cabeça, alta ou queda de pressão! Tudo passou! 
Cada um que persistiu, alcançou! Mais um desafio que superou!

Quando chegavam as provas em nossas mãos!

Hoje estamos aqui concluindo mais essa etapa de crescimento da vida e para saber que aprendemos, é na prática do dia - a - dia, com coragem, fé e alegria!

Alegria nos céus, alegria na terra e muito obrigado a nosso Deus. Reis.

Paróquia São José Operário - Mambucaba; Perequê; Angra dos

Oradora - Creusa das Graças Nascimento Moisés.

Bárbara Bucker, mc Professora do Departamento de Teologia da PUC-Rio 